\title{
Increased serum calpain activity is associated with HMGB1 levels in systemic sclerosis
}

\author{
Ji-Na Zheng ${ }^{1 \dagger}$, Yang $\mathrm{Li}^{2,3 \dagger}$, Yue-Mei Yan ${ }^{1 \dagger}$, Yong Yu, ${ }^{4,5}$, Wen-Qi Shao ${ }^{6}$ and Qiang Wang ${ }^{1 *}$ (D)
}

\begin{abstract}
Background: Systemic sclerosis (SSc) or scleroderma is an intractable autoimmune disorder that affects multiple organs. The objectives were to investigate clinical correlations of serum calpain activity and high mobility group box 1 (HMGB1) levels with immunological and clinical traits.

Methods: A total of 31 patients with SSc, 20 age- and gender-matched healthy control subjects (HC), and 10 patients with other connective tissue diseases (CTD) were recruited in the study. We measured serum calpain activity and HMGB1 levels and analyzed the datasets (GSE40839, GSE48149, GSE76808, GSE81292, GSE33463, and GSE58095) from Gene Expression Omnibus (GEO) database to explore the potential mechanism by which calpain exerts its function through bioinformatics methods.

Results: Serum calpain activity was significantly increased in patients with SSC compared with those in HC and in patients with CTD and was correlated with serum HMGB1 levels, modified Rodnan skin score, erythrocyte sedimentation rate, mean platelet volume, and plateletcrit. Notably, serum calpain activity and HMGB1 levels in SSC patients with interstitial lung disease (ILD) were significantly higher than those in SSc patients without ILD. Serum calpain activity and HMGB1 levels could be the independent risk factors for SSc-ILD and novel biomarkers in patients with SSC.

Conclusion: This is the first study that reports increased serum calpain activity and the correlation between calpain and HMGB1 in patients with SSC or SSc-ILD. The serum calpain activity and HMGB1 levels may serve as measures of ILD in patients with SSc. Also, calpain and HMGB1 could be potential therapeutic targets for patients with SSc or SSC-ILD in the future.
\end{abstract}

Keywords: Systemic sclerosis, Interstitial lung disease, Calpain, HMGB1, Microarray analysis

\section{Background}

Systemic sclerosis (SSc) or scleroderma is an intractable autoimmune disorder characterized by vasculopathy and fibrosis of the skin and visceral organs including the heart, kidney, and lung, which has high mortality and reduced survival than other autoimmune diseases [1].

\footnotetext{
* Correspondence: wangqiang7766@163.com

${ }^{+} \mathrm{Ji}$-Na Zheng, Yang Li and Yue-Mei Yan contributed equally to this work. 'Department of Dermatology, Zhongshan Hospital, Fudan University, No. 180 Fenglin Road, Xuhui District, Shanghai 200032, People's Republic of China Full list of author information is available at the end of the article
}

Although SSc often involves multiple organs, lung diseases, such as interstitial lung disease (ILD) and pulmonary arterial hypertension (PAH), are considered the main causes of mortality [2]. To date, the pathogenesis and mechanism of SSc have been poorly understood. Progress in the development of effective therapies for SSc has been slow [3]. Thus, besides novel biomarkers reflecting the progression of the disease, there is also a need to identify the potential targets for accurate therapy in SSc or SSc-ILD. 
Fibrosis is the most remarkable clinical characteristics of SSc, which leads to impaired organ function and scarring. In epithelial organs, particularly the lung, skin, kidney, and liver, fibrogenesis is triggered by a wide range of initial injuries to the epithelium, such as trauma, toxins, inflammation, and infection [4]. In addition to epithelial tissues, initial damages to endothelium and vascular dysfunction also play important roles in SScrelated vascular damage [5]. However, regardless of the initial injuries, the accumulation of activated myofibroblasts eventually leads to excessive generation of extracellular matrix proteins and disease-related collagen in the connective tissue of multiple organs [6]. Although the explicit origin of activated myofibroblasts in SSc remains varied and uncertain, profibrotic cytokinemediated epithelial-to-mesenchymal transition (EMT) is considered a crucial mechanism for the production of activated myofibroblasts and the development of fibrosis in SSc [7, 8]. Given the key role of EMT in SSc, we reasoned that relevant molecules that are involved in EMT would be attractive therapeutic targets for SSc.

We were interested in the association in the previous studies between various EMT-related and fibrotic diseases and the increased activity or expression of calpains-a family of calcium-dependent, non-lysosomal neutral cysteine endopeptidases [9]. Humans can express 15 calpain genes including CAPN1 to CAPN16 except for $C A P N 4$, which can be categorized as conventional and unconventional subunits [10]. Conventional subunits that comprised of CAPN1 and CAPN2 are the most studied members of the calpain family, and both are ubiquitously expressed in all tissues, which function as the catalytic subunits of calpain-1 and calpain-2, respectively [11, 12]. Calpain small subunit 1 (CAPNS1), also known as CAPN4, is the common regulatory subunit of calpain-1 and calpains- 2 and plays an important role in maintaining the activity and stability of calpain [13]. Notably, calpain activity disorder contributes to the pathogenesis of many EMT-related diseases such as idiopathic pulmonary fibrosis, arterial sclerosis, cardiovascular disorders, and cancers [10]. Several studies have reported that calpain-1 may lead to transforming growth factor- $\beta 1$ induced EMT by mediating the phosphoinositide 3-kinase/Akt signaling pathway in human lung epithelial cells $[14,15]$. Peng et al. reported that selective deletion of endothelial cell calpain reduced cardiac fibrosis and cardiac endothelial cell dysfunction in the mouse model of diabetes [16]. Although there is accumulating evidence that targeted inhibition of calpain serves as a potential therapeutic strategy for calpain-related diseases in animal models and clinical trials, few studies have investigated the roles of calpains in autoimmune diseases [10, 17]. Given the detrimental role of calpains in EMTrelated and fibrotic diseases, we advanced a hypothesis that calpains would be a potential therapeutic target for SSc. In particular, the roles of calpains in the pathogenesis of SSc have never been investigated.

High mobility group box 1 (HMGB1), an endogenous damage-associated molecular pattern (DAMP), is secreted when macrophages and monocytes are activated and is passively released as a consequence of cell damage or necrosis [18]. HMGB1 is also a nuclear nonhistone chromatin-binding protein, which participates in the regulation of transcription and stabilization of nucleosome structure [19]. Several studies have reported that serum HMGB1 level is increased and is associated with platelet-derived microparticles indicating that platelets are a source of DAMP HMGB1 in patients with SSc [20-23]. Moreover, active calpain is also associated with platelet-derived microparticles and is known as a source of active calpain in the blood [24]. Thus, we proposed a novel hypothesis that calpain activity in the serum and the levels of HMGB-1 may be directly correlative. So far, studies concerning the correlation between calpain activity and HMGB1 level in the serum from SSc or SSc-ILD patients are still missing.

In this study, we attempted to investigate clinical correlations of serum calpain activity and HMGB1 levels with immunological and clinical traits in 31 Chinese patients with SSc, 20 healthy control subjects (HC), and 10 patients with other connective tissue diseases (CTD). Furthermore, integrative microarray datasets of lung samples and peripheral blood mononuclear cell (PBMC) samples from patients with SSc or SSc-ILD and HC were utilized to explore the underlying mechanism by which calpain exerts its function in the pathogenesis of SSc through bioinformatic analysis. Our findings may point to serum calpain activity and HMBG1 levels could be promising treatment targets for SSc or SSc-ILD, and provide powerful evidence for better understanding the pathogenesis of SSc.

\section{Methods}

\section{Patients and controls}

A total of 31 patients with a positive diagnosis as SSc according to ACR/EULAR 2013 classification criteria was recruited at Zhongshan Hospital (Fudan University, Shanghai, China) [25]. Ten patients with other CTD were recruited as disease control subjects. Twenty people with no history of pulmonary, autoimmune, cardiovascular, or other diseases were recruited as $\mathrm{HC}$. Detailed characteristics of SSc patients, HC, and patients with other CTD were shown (Table 1). The presence of ILD was defined by the identification of bibasilar fibrosis on chest high-resolution computed tomography or chest radiography [25]. Patients presenting pulmonary vascular resistance $\geq 3$ Wood units, mean arterial systolic pressure $>25 \mathrm{mmHg}$, and pulmonary capillary wedge 
Table 1 Laboratory and clinical characteristics of the patients and control subjects included in the study

\begin{tabular}{|c|c|c|c|c|c|}
\hline Characteristics & All SSC $(\boldsymbol{n}=31)$ & Non-ILD-SSC $(\boldsymbol{n}=10)$ & SSC-ILD $(\boldsymbol{n}=21)$ & Other CTD $(\boldsymbol{n}=10)$ & $\mathrm{HC}(\boldsymbol{n}=20)$ \\
\hline Age (mean \pm SD) & $51 \pm 13$ & $49 \pm 14$ & $53 \pm 12$ & $47 \pm 11$ & $40 \pm 11$ \\
\hline Female, $n(\%)$ & $27(87)$ & $10(91)$ & $17(85)$ & $8(80)$ & $17(85)$ \\
\hline Course of disease (mean \pm SD) & $8 \pm 7$ & $8 \pm 8$ & $9 \pm 8$ & NA & \\
\hline ISSc/dSSc \% & $55 / 45$ & $45 / 55$ & $60 / 40$ & & \\
\hline $\mathrm{PAH}, n(\%)$ & $3(10)$ & $0(0)$ & $3(15)$ & & \\
\hline Raynaud's phenomenon, $\boldsymbol{n}(\%)$ & $28(90)$ & $9(82)$ & $19(45)$ & & \\
\hline Anti-Scl-70 antibody, $n$ (\%) & $13(42)$ & $4(36)$ & $9(45)$ & & \\
\hline ANA, $n(\%)$ & $30(97)$ & $10(91)$ & $20(100)$ & & \\
\hline Anti-RNP, $n(\%)$ & $8(26)$ & $4(36)$ & $4(20)$ & & \\
\hline Anti-centromere, $n$ (\%) & $8(26)$ & $2(18)$ & $6(30)$ & & \\
\hline mRSS (mean \pm SD) $n=25$ & $12 \pm 10$ & $21 \pm 14$ & $10 \pm 7$ & & \\
\hline Immunosuppressive therapy ever, $n$ (\%) & $11(35)$ & $5(45)$ & $6(25)$ & & \\
\hline Cyclophosphamide, $n$ (\%) & $6(19)$ & $3(27)$ & $3(15)$ & & \\
\hline Methotrexate, $n$ (\%) & $2(6)$ & $0(0)$ & $2(5)$ & & \\
\hline Mycophenolate mofetil, $n$ (\%) & $3(10)$ & $2(18)$ & $1(5)$ & & \\
\hline FVC $\%$ predicted, $n=17$ (mean \pm SD) & $74.5 \pm 14.2$ & $78 \pm 8.5$ & $75.6 \pm 16.2$ & & \\
\hline $\mathrm{DL}_{\mathrm{CO}} \%$ predicted, $n=8($ mean $\pm \mathrm{SD})$ & $74.2 \pm 22.3$ & $70.9 \pm 3.5$ & $76.2 \pm 27.8$ & & \\
\hline FEV1/FVC\%, $n=17($ mean \pm SD) & $85.5 \pm 11.6$ & $76.2 \pm 7.5$ & $88.4 \pm 11.1$ & & \\
\hline $\mathrm{ESR}, \mathrm{mm} / \mathrm{h}($ mean $\pm \mathrm{SD})$ & $17.10 \pm 11$ & $17.80 \pm 14.36$ & $16.76 \pm 9.13$ & & \\
\hline $\mathrm{PLT}, 10^{9} / \mathrm{L}($ mean $\pm \mathrm{SD})$ & $206 \pm 67$ & $209.40 \pm 79.98$ & $204.62 \pm 61.60$ & & \\
\hline MPV, fL (mean \pm SD) & $11.95 \pm 1.49$ & $11.23 \pm 1.95$ & $10.81 \pm 1.24$ & & \\
\hline PDW, fL (mean \pm SD) & $0.22 \pm 0.07$ & $0.23 \pm 0.08$ & $0.22 \pm 0.07$ & & \\
\hline $\mathrm{PCT}, \%($ mean $\pm \mathrm{SD})$ & $31.17 \pm 11.13$ & $34.69 \pm 14.07$ & $29.49 \pm 9.36$ & & \\
\hline $\mathrm{P}-\mathrm{LCR}, \%($ mean $\pm \mathrm{SD})$ & $13.47 \pm 3.30$ & $14.12 \pm 4.50$ & $13.16 \pm 2.63$ & & \\
\hline $\mathrm{RA}, n(\%)$ & NA & & & $1(10)$ & NA \\
\hline ANCA-associated vasculitis, $n$ (\%) & & & & $1(10)$ & \\
\hline SLE, $n(\%)$ & & & & $2(20)$ & \\
\hline SS, $n(\%)$ & & & & $1(10)$ & \\
\hline Dermatomyositis, $n$ (\%) & & & & $2(20)$ & \\
\hline Polymyositis, $n$ (\%) & & & & $3(30)$ & \\
\hline
\end{tabular}

Abbreviations: SSC systemic sclerosis, ILD interstitial lung disease, $P A H$ pulmonary arterial hypertension, CTD connective tissue diseases, $H C$ healthy control subjects, $S D$ standard deviation, dSSC diffuse cutaneous systemic sclerosis, ISSC limited cutaneous systemic sclerosis, ANA antinuclear antibodies, anti-RNP antiribonucleoprotein antibody, mRSS modified Rodnan skin score, $F V C$ forced vital capacity, $D L_{C O}$ diffusing capacity of the lung for carbon monoxide, $F E V 1$ forced the first second of expiratory volume, ESR erythrocyte sedimentation rate, PLT platelet count, PDW platelet distribution width, PCT plateletcrit, MPV mean platelet volume, $P$-LCR platelet large cell ratio, RA rheumatoid arthritis, ANCA anti-neutrophil cytoplasmic antibodies, SLE systemic lupus erythematosus, SS Sjogren syndrome, $N A$ not available

pressure $\leq 15 \mathrm{mmHg}$ were defined as PAH [26]. The study was approved by the Zhongshan Hospital Research Ethics Committee. Written informed consent was acquired from all subjects.

\section{Blood sampling}

Blood samples were collected in serum tubes with a gel separation plug (BD Biosciences, USA). All samples were gently mixed, and the serum tubes were placed at room temperature for coagulation for $30 \mathrm{~min}$. Then, all samples were then centrifuged at $3000 \mathrm{~g}$ for $20 \mathrm{~min}$ at $4{ }^{\circ} \mathrm{C}$ and the top volumes of the serum were collected in 1.5$\mathrm{mL}$ centrifuge tubes (Axygen, USA). All samples were frozen within $30 \mathrm{~min}$ and preserved at $-80^{\circ} \mathrm{C}$ before tests. Further detection was done within 1 month.

\section{Calpain activity measurement}

Calpain activity kit (Raybiotech, USA) was utilized to measure calpain activities in serum or plasma. Eightyfive microliters of serum was diluted in $10 \mu \mathrm{L}$ of $10 \mathrm{X}$ calpain reaction buffer and $5 \mu \mathrm{L}$ of calpain substrate AcLLY-AFC with or without $100 \mu \mathrm{M}$ calpeptin (Abmole, 
USA). Free AFC was quantified using a fluorometer (excitation $\lambda 400 \mathrm{~nm}$, emission $\lambda 505 \mathrm{~nm}$ ) after incubating at $37^{\circ} \mathrm{C}$ for $1 \mathrm{~h}$ in the dark. The difference of calpain activity was determined by comparing the relative fluorescent unit (RFU) of samples with and without calpeptin. The calpain activity was expressed as RFU per microliter serum of each sample.

\section{Measurement of HMGB-1 concentrations in serum}

The measurement of the serum HMGB-1 level was performed by enzyme-linked immunosorbent assays (IBLInternational, Hamburg, Germany) according to the manufacturer's instructions. The detection limit of this assay was $0.313 \mathrm{ng} / \mathrm{mL}$. Each sample was tested in duplicate.

\section{Data information}

Microarray datasets and high-throughput sequencing datasets from NCBI Gene Expression Omnibus (GEO) (https://www.ncbi.nlm.nih.gov/geo/) were thoroughly searched for available datasets involving SSc. Included datasets should meet the following criteria: (a) datasets with SSc or SSc-ILD lung tissue, skin, or blood samples; (b) datasets with platform information; and (c) datasets with healthy people as control. According to these criteria, six microarray datasets (GSE40839, GSE48149, GSE76808, GSE81292, GSE33463, and GSE58095) were obtained from the GEO database. Details of each microarray study, including sample descriptions and platform information, are shown in Table S1.

\section{Data processing}

For datasets of lung tissue samples (GSE40839, GSE48149, GSE76808, and GSE81292), 50 SSc-ILD patients and $28 \mathrm{HC}$ were included for further analysis. For datasets of PBMC samples (GSE33463), 69 SSc-ILD patients and $41 \mathrm{HC}$ were included. For datasets of skin biopsy samples, 59 SSc patients and $43 \mathrm{HC}$ were included. First, the raw data of each dataset was preprocessed by the $R$ packages affy (under the $R$ environment, version 3.6.1) and annotate methods to make normalized expression profiles with official gene names. Since datasets of lung samples were from different studies and based on different platforms, all lung samples of five datasets (GSE40839, GSE48149, GSE76808, and GSE81292) were integrated by batch normalization using sva package in $\mathrm{R}$ software to reduce batch effects and heterogeneity among different samples to significantly improve sample size (50 SSc-ILD vs $28 \mathrm{HC}$ ). Next, the differential expression analysis $\left(\log _{2} \mathrm{FC}>|1|, \quad p\right.$ value $\left.<0.05\right)$ of calpain-related genes was performed by comparing SSc or SSc-ILD samples to HC samples using the limma package. The boxplot was also utilized to visualize the expression of calpain-related genes.

\section{Bioinformatic analysis}

To explore the function of calpain-related genes in SSc patients, we removed HC lung samples $(n=20)$ and clustered SSc-ILD patients $(n=50)$ into two clusters based on the expression status of calpain-related genes using "ConsensusClusterPlus" package in R [27]. Then, the differential expression analysis was performed using the limma package in two clusters. The cutoff value was $\log _{2} \mathrm{FC}>|1|, p$ value $<0.05$. Next, Kyoto Encyclopedia of Genes and Genomes (KEGG) and Gene Ontology (GO) analysis of differently expressed genes (DEGs) in two clusters were performed using GOplot package in R. To build the protein-protein interaction (PPI) network, we imported the genes into STRING database (http://string$\mathrm{db} . o r g$ ) and visualized these genes by Cytoscape.

\section{Statistical analysis}

We utilized the Student $t$ test, the Mann-Whitney $U$ test, or the chi-squared test, as appropriate, to test comparisons of each group for statistical significance, and used univariate logistic regression (ULR) and multivariate logistic regression (MLR) to determine risk factors by SPSS 22.0. We also utilized the receiver operating characteristic curve (ROC) to calculate the area under the curve (AUC) by SPSS 22.0 and utilized Spearman's rank correlation to evaluate the correlation between two continuous parameters by GraphPad Prism 6.0. A $p$ value of $<0.05$ was considered statistically significant.

\section{Results}

Laboratory and clinical characteristics of the patients and controls

SSc patients and $\mathrm{HC}$ with matched age and gender showed no significant differences (Table 1). Moreover, we found that there were no significant differences between laboratory and clinical parameters in SSc patients with and without ILD (Table 1).

\section{Overexpression of calpain-related genes in SSC or SSC-ILD patients}

To explore the relationship between calpains and SSc, we compared the expression levels of calpain-related genes between SSc or SSc-ILD patients and HC in five microarray datasets from lung biopsy samples, one from PBMC samples and one from skin biopsy samples. For the comparison of integrated microarray datasets of lung samples, the expression levels of CAPN1, CAPNS1, $C A P N 6$, and CAPN7 were significantly higher in lung samples from SSc-ILD patients than in those from HC (Fig. 1a, 50 SSc-ILD versus $28 \mathrm{HC}$ ). For the comparison of PBMC samples, the expression levels of CAPN1, CAPN5, CAPN11, and CAPN12 were significantly higher in PBMC samples from SSc patients than in those from $\mathrm{HC}$ (Fig. 1b, 69 SSc versus $41 \mathrm{HC}$ ). For the comparison 


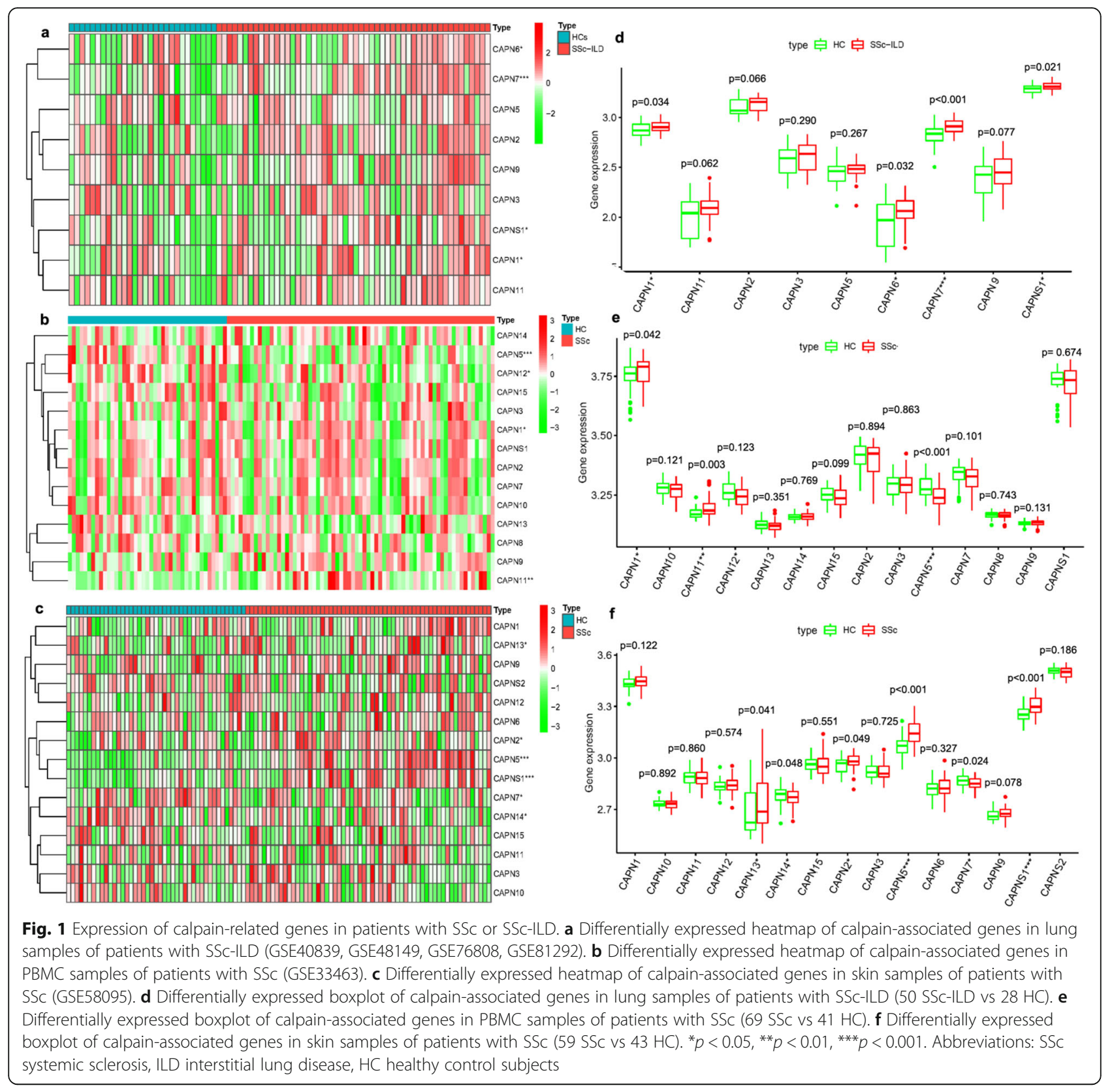

of skin biopsy samples, the expression levels of CAPNS1, CAPN2, CAPN5, CAPN7, CAPN13, and CAPN14 were significantly higher in skin samples from SSc patients than in those from $\mathrm{HC}$ (Fig. 1c, 59 SSc versus $43 \mathrm{HC}$ ). Notably, the differential expression of CAPN1 was overlapped in these microarray datasets from lung samples and PBMC samples (Fig. 1d, e, $p=0.034$, and $p=0.042$, respectively). Moreover, differential expression of CAPNS1 and CAPN7 were overlapped in these microarray datasets from lung samples and skin samples (Fig. 1d, f, $p=0.021$ and $p<0.001 ; p<0.001$ and $p=$ 0.024 , respectively). These results indicated a significant overexpression of CAPN1, CAPNS1, and CAPN7 in patients with SSc. Therefore, calpain activity was measured in serum from SSc and SSc-ILD patients to further verify the overexpression of calpains.

\section{Serum calpain activity and HMGB1 level were increased in SSc patients}

SSc patients showed significantly increased calpain activity in serum compared with $\mathrm{HC}(p<0.05)$ and patients with other CTD $(p<0.05$; Fig. 2a). Serum calpain activity in patients with diffuse cutaneous systemic sclerosis (dSSc) was significantly higher than that in patients with limited cutaneous systemic sclerosis (ISSc) $(p<0.05$; Fig. 2b). Serum calpain activity in patients with SSc-ILD 

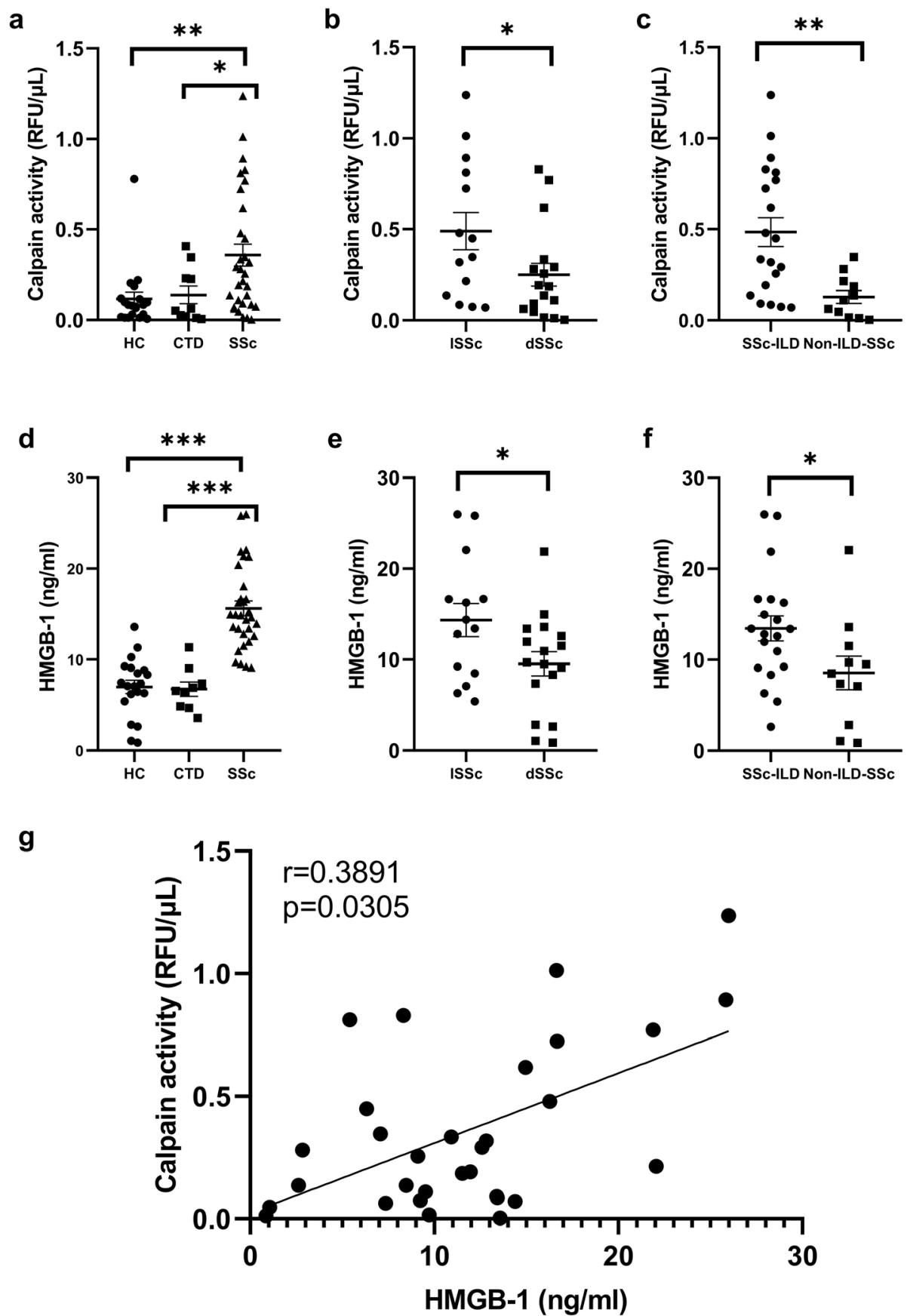

Fig. 2 Increased serum calpain activity and HMGB1 levels in SSc patients. a Significantly higher serum calpain activity and HMGB1 levels (d) were found in SSC patients than in HC and in patients with other CTD. b Patients with dSSC showed significantly higher serum calpain activity and HMGB1 levels (e) than patients with ISSc. c SSC patients with ILD showed significantly higher serum calpain activity and HMGB1 levels (f) than SSC patients without ILD. g Correlations between serum calpain activity and HMGB1 levels from patients with SSc. The short bar indicates mean \pm 2 SD in each group. ${ }^{* * *}<0.001,{ }^{* *}<0.01,{ }^{*}<0.05$. Abbreviations: SSC systemic sclerosis, ILD interstitial lung disease, CTD connective tissue diseases, HC healthy control subjects, SD standard deviation, dSSC diffuse cutaneous systemic sclerosis, ISSc limited cutaneous systemic sclerosis

was significantly higher than that in SSc patients without ILD $(p<0.05 ;$ Fig. 2c). Furthermore, SSc patients showed significantly elevated HMGB1 level in serum compared with $\mathrm{HC}(p<0.001)$ and patients with other CTD $(p<0.001$; Fig. 2d). Serum HMGB1 levels in patients with dSSc were significantly elevated relative to patients with 1SSc $(p<0.05$; Fig. 2e). Serum HMGB1 levels in patients with SSc-ILD were significantly elevated in comparison to SSc patients without ILD $(p<0.05$; Fig. 2f). To further assess the relationship 
between serum calpain activity and HMGB1 in the pathogenesis of SSc, we evaluated whether serum calpain activity was correlated with serum HMGB1 level and found that serum calpain activity was correlated positively with HMGB1 level $(r=0.3891, p<0.05$; Fig. $2 \mathrm{~g})$.

\section{Clinical and laboratory correlation}

Next, we evaluated the clinical and laboratory correlation of serum calpain activity and HMGB1 level in SSc patients (Table 2). The cutoff value was set at $0.437 \mathrm{RFU} / \mu \mathrm{L}$ for calpain activity and $13.37 \mathrm{ng} / \mathrm{mL}$ for HMGB1 concentration, which was calculated as the mean +2 SD for HC. A total of 10 patients were defined as the calpain high group, while the remaining 21 patients were defined as the calpain low group. For HMGB1 level, a total of 12 patients were defined as the HMGB1 high group, while the remaining 19 patients were defined as the HMGB1 low group. SSc patients with serum-elevated calpain activity had significantly higher frequency of negative anti-Scl-70 antibody $(p<$ $0.05)$, higher modified Rodnan skin score (mRSS) $(p<$ $0.05)$, higher plateletcrit (PCT) $(p<0.05)$, higher platelet large cell ratio (P-LCR) $(p<0.05)$, and decreased erythrocyte sedimentation rate (ESR) $(p<0.05)$. Furthermore, serum calpain activity was correlated positively with mRSS $(r=0.4990, p<0.05)$, mean platelet volume (MPV) $(r=0.3682, p<0.05)$, and PCT $(r=0.3988, p<$ $0.05)$ and was correlated inversely with ESR ( $r=-$ 0.4186, $p<0.05$; Fig. 3). However, serum HMGB1 level showed no significant correlations with any clinical and laboratory parameters. Therefore, these results suggested elevated serum calpain activity was associated with the skin thickness, ESR, anti-Scl-70 antibody, and platelet abnormalities in patients with SSc.

\section{Diagnostic value of serum calpain activity and HMGB1 levels}

Next, we applied ULR and MLR and found that mRSS, serum calpain activity, and HMGB1 levels could become independent risk factors for SSc-ILD in SSc patients (Table 3). However, the results of MLR analyses indicated that serum calpain activity and HMGB1 levels were not significantly correlated with the diagnosis of SSc-ILD (Table 3). Next, to explore the diagnostic capabilities of serum calpain activity and HMGB1 levels for patients with SSc or SSc-ILD, we performed ROC that

Table 2 Clinical and laboratory characteristics of SSc patients according to serum calpain activity and HMGB1 levels

\begin{tabular}{|c|c|c|c|c|c|c|}
\hline Characteristics & Calpain ${ }^{\text {high }}, \boldsymbol{n}=10$ & Calpain ${ }^{\text {low }}, \boldsymbol{n}=21$ & $\boldsymbol{p}$ value & HMGB-1 $^{\text {high }}, \boldsymbol{n}=12$ & HMGB-1 low, $\boldsymbol{n}=19$ & $\boldsymbol{p}$ value \\
\hline Age (mean \pm SD) & $48 \pm 13$ & $53 \pm 13$ & 0.311 & $49 \pm 14$ & $53 \pm 12$ & 0.358 \\
\hline Female, $n(\%)$ & $8(80)$ & $19(90)$ & 0.577 & $11(92)$ & $16(84)$ & 0.958 \\
\hline Course of disease (mean \pm SD) & $10 \pm 11$ & $7 \pm 6$ & 0.299 & $7 \pm 2$ & $8 \pm 2$ & 0.946 \\
\hline dSSc/ISSc & $5 / 5$ & $12 / 9$ & 0.709 & $8(67)$ & $6(32)$ & 0.075 \\
\hline $\mathrm{PAH}, n$ (\%) & $2(20)$ & $3(14)$ & 0.690 & $4(33)$ & $1(5)$ & 0.060 \\
\hline SSc-ILD, $n$ (\%) & $8(80)$ & $16(76)$ & 0.813 & $11(92)$ & $13(68)$ & 0.201 \\
\hline Raynaud's phenomenon, $n$ (\%) & $9(90)$ & $18(86)$ & 0.734 & $11(92)$ & $16(84)$ & 0.958 \\
\hline Anti-Scl-70 antibody, $n$ (\%) & $1(10)$ & $12(57)$ & $0.020^{*}$ & $5(42)$ & $8(42)$ & 0.981 \\
\hline ANA, $n(\%)$ & $10(100)$ & $20(95)$ & 0.483 & $12(100)$ & $18(95)$ & 0.999 \\
\hline Anti-RNP, $n(\%)$ & $4(40)$ & $4(19)$ & 0.381 & $4(33)$ & $4(21)$ & 0.676 \\
\hline Anti-centromere, $n$ (\%) & $3(30)$ & $5(24)$ & 0.715 & $5(42)$ & $3(16)$ & 0.206 \\
\hline mRSS (mean \pm SD) $n=26$ & $19 \pm 13$ & $9 \pm 6$ & $0.012^{*}$ & $9 \pm 5$ & $15 \pm 12$ & 0.098 \\
\hline FVC $\%$ predicted, $n=17($ mean \pm SD $)$ & $64.85 \pm 35.29$ & $54.27 \pm 35.40$ & 0.545 & $52.63 \pm 33.50$ & $63.80 \pm 36.46$ & 0.472 \\
\hline $\mathrm{DL}_{\mathrm{CO}} \%$ predicted, $n=8($ mean $\pm \mathrm{SD})$ & $81.74 \pm 32.99$ & $66.57 \pm 11.25$ & 0.488 & $61.35 \pm 20.29$ & $80.79 \pm 27.21$ & 0.387 \\
\hline FEV1/FVC\% $n=17($ mean \pm SD $)$ & $88.42 \pm 15.84$ & $85.53 \pm 8.49$ & 0.638 & $83.58 \pm 9.22$ & $88.97 \pm 12.79$ & 0.344 \\
\hline $\mathrm{ESR}, \mathrm{mm} / \mathrm{h}($ mean $\pm \mathrm{SD})$ & $11.10 \pm 5.04$ & $19.95 \pm 11.77$ & $0.031^{*}$ & $13.92 \pm 8.45$ & $19.11 \pm 11.90$ & 0.167 \\
\hline Platelets count, $10^{9} / \mathrm{L}$ (mean \pm SD) & $201 \pm 71$ & $209 \pm 66$ & 0.772 & $194 \pm 83$ & $214 \pm 56$ & 0.442 \\
\hline MPV, fL (mean \pm SD) & $11.59 \pm 1.66$ & $10.64 \pm 1.33$ & 0.096 & $11.25 \pm 1.82$ & $10.75 \pm 1.25$ & 0.373 \\
\hline PDW, fL (mean \pm SD) & $0.22 \pm 0.07$ & $0.22 \pm 0.07$ & 0.867 & $0.21 \pm 0.08$ & $0.23 \pm 0.06$ & 0.480 \\
\hline $\mathrm{PCT}, \%($ mean $\pm \mathrm{SD})$ & $37.74 \pm 11.69$ & $28.04 \pm 9.62$ & $0.021^{*}$ & $30.98 \pm 12.95$ & $31.29 \pm 10.20$ & 0.944 \\
\hline $\mathrm{P}-\mathrm{LCR}, \%($ mean $\pm \mathrm{SD})$ & $15.17 \pm 3.94$ & $12.66 \pm 2.68$ & $0.045^{*}$ & $14.08 \pm 4.01$ & $13.08 \pm 2.81$ & 0.465 \\
\hline
\end{tabular}

Abbreviations: SSC systemic sclerosis, ILD interstitial lung disease, $P A H$ pulmonary arterial hypertension, $H C$ healthy control subjects, SD standard deviation, dCSSC diffuse cutaneous systemic sclerosis, ICSSc limited cutaneous systemic sclerosis, ANA antinuclear antibodies, anti-RNP anti-ribonucleoprotein antibody, mRSS modified Rodnan skin score, $F V C$ forced vital capacity, $D L_{C O}$ diffusing capacity of the lung for carbon monoxide, $F E V 1$ forced the first second of expiratory volume, ESR erythrocyte sedimentation rate, $P L T$ platelet count, $P D W$ platelet distribution width, $P C T$ plateletcrit, MPV mean platelet volume, $P$-LCR platelet large cell ratio, ANCA anti-neutrophil cytoplasmic antibodies, NA not available. ${ }^{*} p<0.05$ 


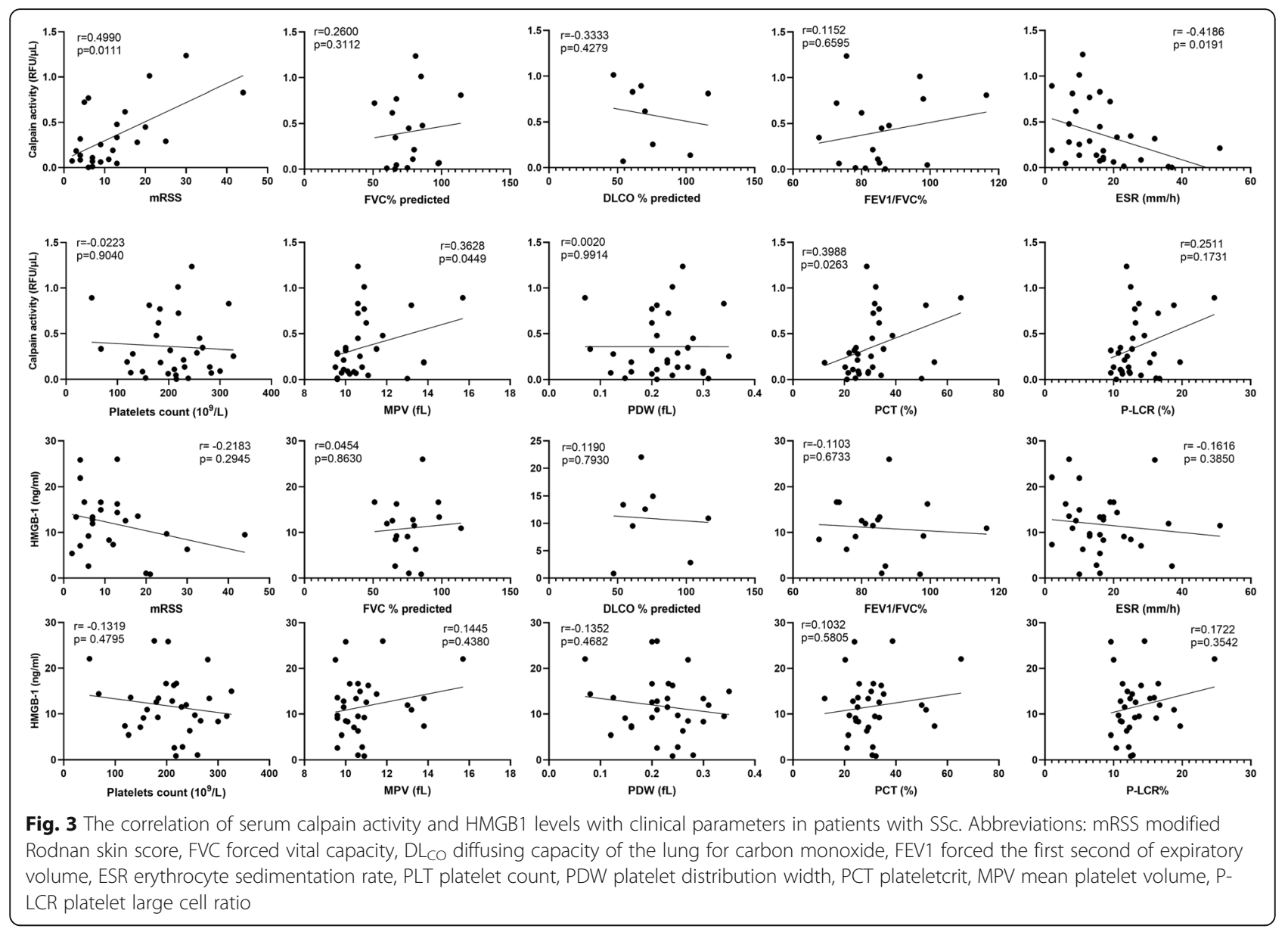

the AUC was $0.750(p<0.05)$ for serum calpain activity, $0.746(p<0.05)$ for HMGB1 levels, and $0.824(p<0.001)$ for the combination of them (Fig. 4a). Then, we confirmed the potential utility of serum calpain activity and HMGB1 levels as novel diagnostic biomarkers of SScILD. The AUC for serum calpain activity, HMGB1 levels, and combination of them when distinguishing SSc-ILD patients from SSc patients were 0.781 $(p<0.05), 0.767(p<0.05)$, and $0.833(p<0.05)$ (Fig. 4b). In summary, the above results indicated a high diagnostic accuracy of serum calpain activity and HMGB1 levels as a new biomarker for SSc or SSc-ILD and they could be the independent risk factors for SSc-ILD.

\section{Underlying mechanisms in SSc or SSc-ILD}

To further explore the biological role of calpain-related genes and underlying mechanisms in SSc or SSc-ILD, we removed 28 lung samples from $\mathrm{HC}$ and clustered 50 lung samples from SSc-ILD into two groups using the ConsensusClusterPlus package. On the basis of the expression similarity of calpain-related genes, $k=2$ seemed to be an adequate selection with clustering stability increasing from $k=2$ to 10 (Fig. S1a, b and c). Next, we used the differential expression analysis of cluster1 relative to cluster2 to confirm differentially expressed genes associated with calpain expression. Seventy-two upregulated and 65 downregulated genes were identified to be significantly associated with calpain-related gene expression between cluster1 and cluster2 (Fig. S1d). These abnormal genes were also shown as an expression heatmap (Fig. S1e). Then, we identified these aberrant genes through the PPI network (Fig. S1f). GO enrichment analysis revealed that these genes were mainly distributed in reproductive structure development, reproductive system development, cornification, renal system development, and urogenital system development (Fig. 5a). Moreover, to understand the biological mechanism associated with SSc or SSc-ILD, we performed KEGG analysis of these abnormal genes. These genes were mainly distributed in genes encoding for transcriptional misregulation in cancer, toll-like receptor signaling pathway, pancreatic secretion and complement, and coagulation cascades, suggesting that the levels of these pathways were correlated with SSc or SSc-ILD advances (Fig. 5b). 
Table 3 Univariate and multivariate logistic regression of clinical and laboratory parameters to ILD in patients with SSC

\begin{tabular}{|c|c|c|c|c|c|c|}
\hline \multirow[t]{2}{*}{ Hub genes/clinical traits } & \multicolumn{3}{|c|}{ Univariate logistic regression } & \multicolumn{3}{|c|}{ Multivariate logistic regression } \\
\hline & OR & $95 \% \mathrm{Cl}$ & $\boldsymbol{p}$ value & OR & $95 \% \mathrm{Cl}$ & $\boldsymbol{p}$ value \\
\hline Gender & 1.578 & $0.218,7.618$ & 0.929 & & & \\
\hline Age & 0.943 & $0.878,1.013$ & 0.108 & & & \\
\hline Course of disease & 0.991 & $0.898,1.093$ & 0.857 & & & \\
\hline Raynaud's phenomenon & 0.421 & $0.050,3.532$ & 0.425 & & & \\
\hline Anti-Scl-70 antibody (+) & 2.121 & $0.428,10.515$ & 0.357 & & & \\
\hline ANA (+) & 0.970 & $0.982,1.0010$ & 0.834 & & & \\
\hline Anti-RNP (+) & 0.353 & $0.066,1.874$ & 0.221 & & & \\
\hline Anti-centromere $(+)$ & 4.500 & $0.471,42.970$ & 0.191 & & & \\
\hline mRSS & 0.876 & $0.770,0.997$ & $0.044^{*}$ & 0.917 & $0.807,1.042$ & 0.184 \\
\hline FVC (\%predict) & 1.003 & $0.973,1.033$ & 0.865 & & & \\
\hline DL $\mathrm{L}_{\mathrm{CO}}$ (\%predict) & 1.071 & $0.934,1.228$ & 0.325 & & & \\
\hline FEV1/FVC\% & 1.087 & $0.944,1.253$ & 0.245 & & & \\
\hline $\mathrm{ESR}, \mathrm{mm} / \mathrm{h}$ & 0.991 & $0.925,1.062$ & 0.800 & & & \\
\hline $\mathrm{PLT}, 10^{9} / \mathrm{L}$ & 0.999 & $0.987,1.010$ & 0.850 & & & \\
\hline$M P V, f L$ & 0.829 & $0.503,1.365$ & 0.461 & & & \\
\hline PDW, fL & 0.282 & $0.000,21.236$ & 0.825 & & & \\
\hline PCT, \% & 0.959 & $0.895,1.028$ & 0.235 & & & \\
\hline P-LCR, \% & 0.916 & $0.730,1.149$ & 0.449 & & & \\
\hline Calpain activity & 1.057 & $1.002,1.115$ & $0.041^{*}$ & 1.063 & $0.968,1.166$ & 0.202 \\
\hline HMGB1 & 1.190 & $1.006,1.408$ & $0.043^{*}$ & 1.414 & $0.953,2.096$ & 0.085 \\
\hline
\end{tabular}

Abbreviations: $\mathrm{Cl}$ confidence interval, OR odds ratio, SSC systemic sclerosis, ILD interstitial lung disease, ANA antinuclear antibodies, anti-RNP anti-ribonucleoprotein antibody, mRSS modified Rodnan skin score, FVC forced vital capacity, $D L_{c o}$ diffusing capacity of the lung for carbon monoxide, FEV1 forced the first second of expiratory volume, ESR erythrocyte sedimentation rate, $P L T$ platelet count, $P D W$ platelet distribution width, $P C T$ plateletcrit, MPV mean platelet volume, $P$ - LCR platelet large cell ratio, $R A$ rheumatoid arthritis, ANCA anti-neutrophil cytoplasmic antibodies, NA not available ${ }^{*} p<0.05$
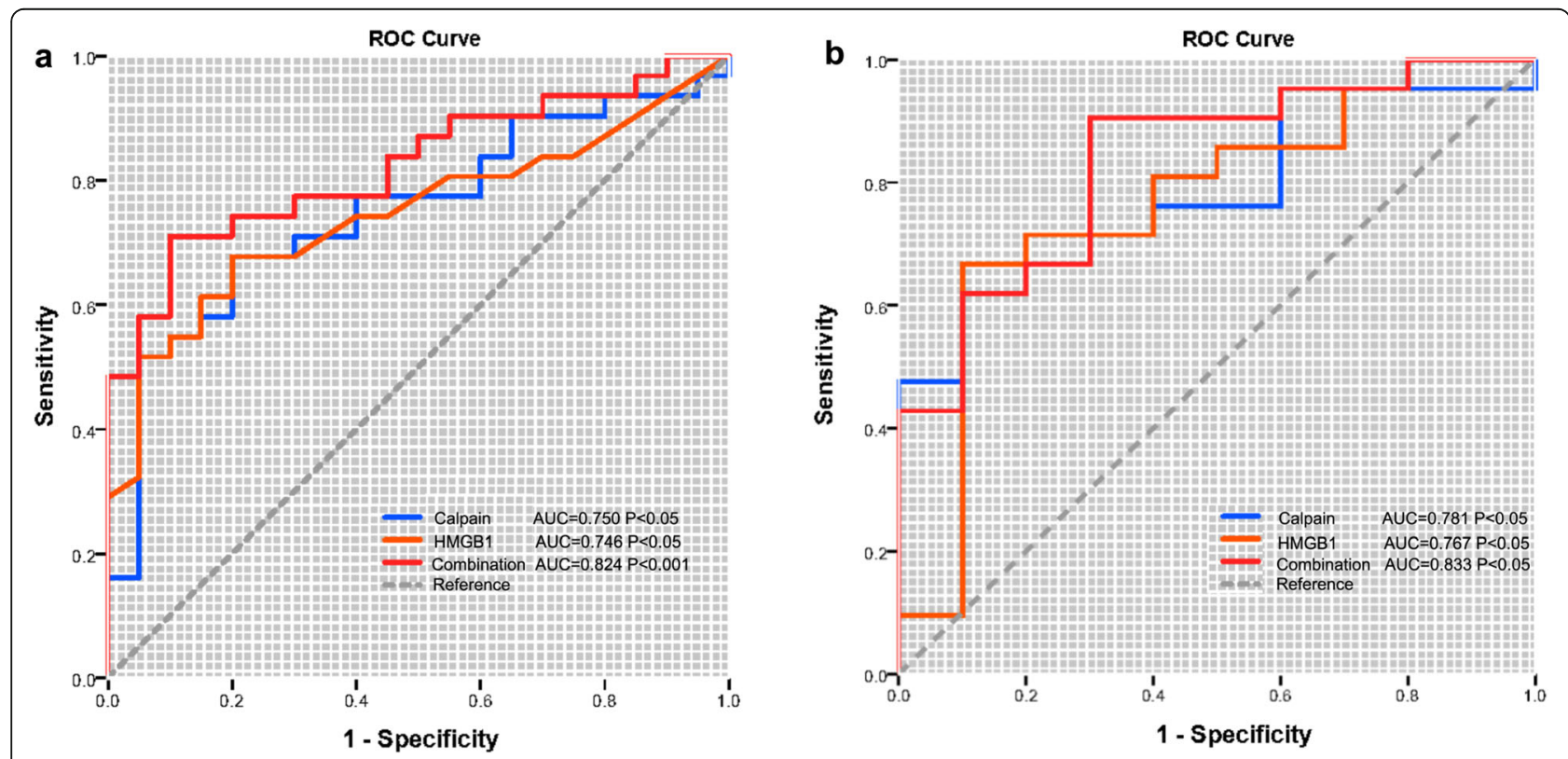

Fig. 4 Receiver operating characteristic curve (ROC). Serum calpain activity and HMGB1 levels for the diagnosis of patients with SSC (a) or SSC-ILD (b) 


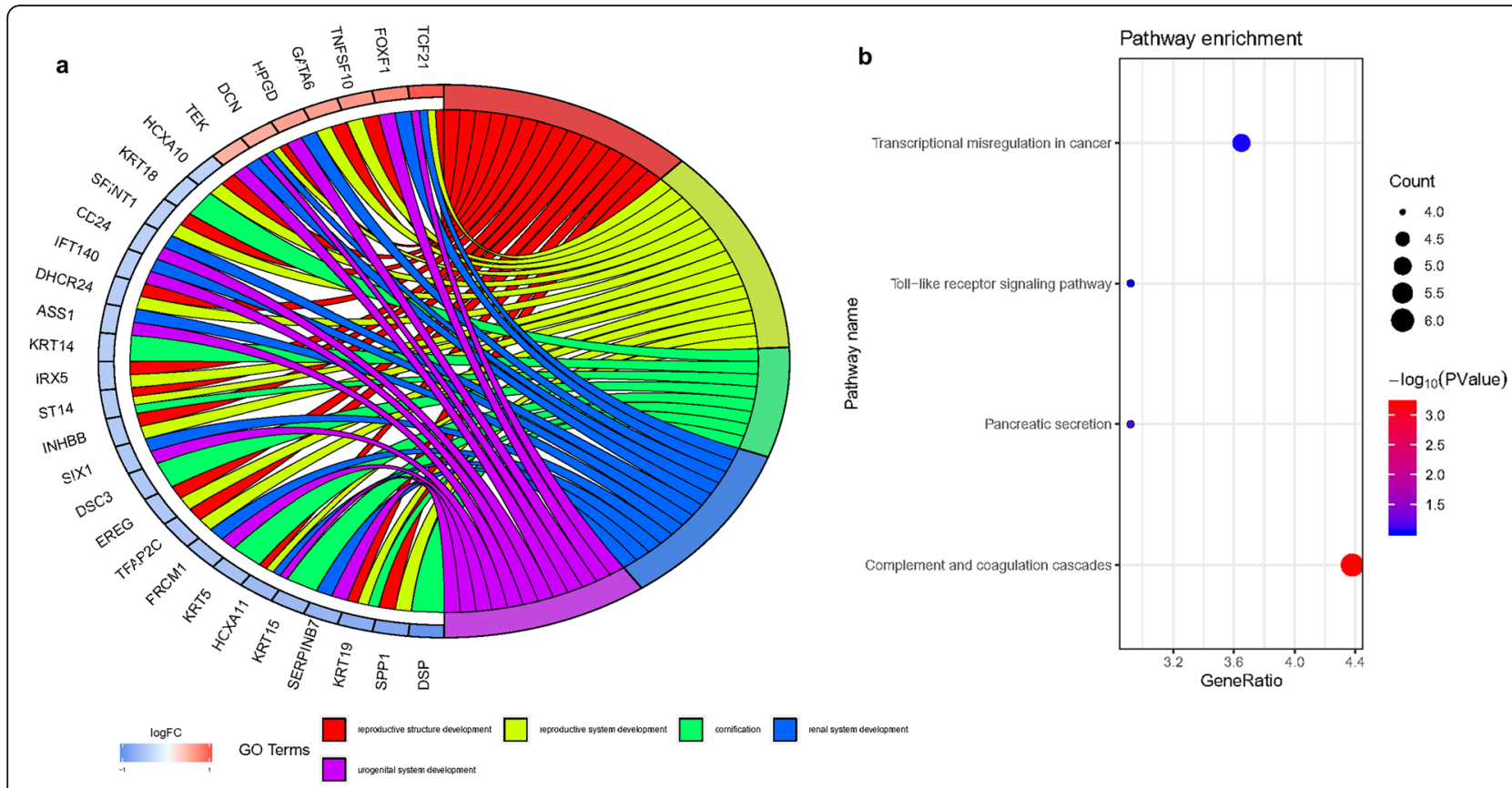

Fig. 5 KEGG pathway and GO enrichment analysis. a The top 5 GO enrichment pathways of differentially expressed genes between cluster 1 and cluster2. $\mathbf{b}$ The size of each circle means the amounts of genes. The different color of each circle means $p$ value. GeneRatio means the number of genes in differentially expressed genes that belong to this pathway divided by the number of genes in the background gene cluster that belong to this pathway. Abbreviations: GO gene ontology, KEGG Kyoto Encyclopedia of Genes and Genomes

\section{Discussion}

The present study is the first to reveal that calpain activity was increased in serum samples from SSc patients in comparison to $\mathrm{HC}$ and patients with other CTD. We also demonstrated that calpain activity in serum of patients with SSc was positively correlated with HMGB1 levels, mRSS, MPV, and PCT, but correlated inversely with ESR. Moreover, the elevation of serum calpain activity was accompanied by the presence of increased mRSS, PCT, and P-LCR; negative anti-Scl-70 antibody; and decreased ESR, indicating that serum calpain activity was associated with platelet dysfunction and skin thickness. Furthermore, serum-elevated calpain activity and HMGB1 levels were also independent risk factors for SSc-ILD. Finally, we explored the potential mechanisms and provided new insights into the pathogenesis of SSc or SSc-ILD. Collectively, our research suggested that serum calpain activity and HMGB1 levels were a new potential serological biomarker for the diagnosis of SScILD. In addition, calpain and HMGB1 could be therapeutic targets for accurate therapy of SSc or SSc-ILD in the future.

Calpain has been widely studied to play a critical role in vascular remodeling and collagen synthesis $[28,29]$. Peng and colleagues reported that calpain induces myocardial hypertrophy and fibrosis [8]. Several studies have reported that inhibition of calpain attenuates bleomycin-induced pulmonary fibrosis in mice [30-33]. Furthermore, a recent study has demonstrated that calpain activation by the renin-angiotensin system induces collagen-I synthesis and pleural fibrosis [34]. However, studies involving the calpain activation and skin fibrosis or SSc-related pulmonary fibrosis have never been reported. It is worth mentioning that our study is the first clinical research that provides insightful viewpoints in the relationship between calpain activation and SSc or SSc-ILD and has demonstrated that increased serum calpain activity is associated with skin thickness and could predict the development of ILD in SSc patients. Moreover, several studies have demonstrated that microparticles are higher in the blood of patients with SSc compared with $\mathrm{HC}$ and that most of them are derived from platelets, indicating that platelet could be a critical factor in the activation of innate immunity $[35,36]$. Manfredi and colleagues have revealed that platelet-derived microparticles express DAMP HMGB1 and lead to initiate fibrosis and endothelial damage when injected into mice, indicating that platelet-associated HMGB1 may be a potential indicator of SSc [22]. Consistent with previous findings, our results also showed that serum calpain activity was correlated with serum HMGB1 levels and plateletrelated parameters (MPV, PCT, and P-LCR), which suggest that activated platelet-derived calpain and HMGB1 may be responsible for the vascular remodeling and endothelial damage in patients with SSc. 
HMGB1 has been widely reported as a central role in the pathogenesis of many CTD, such as SLE, polymyositis or dermatomyositis with ILD, and RA [37-41]. Our results clearly demonstrate that serum HMGB1 levels from SSc patients are significantly higher compared with those from HC. A consistent finding has also been reported in a cohort of 70 patients with SSc and $25 \mathrm{HC}$, which indicates that increased HMGB-1 levels have more frequent involvement of multiple organs and abnormalities of immunological parameters and correlate positively with mRSS [20]. Several mechanisms have heen reported for HMGB1 to contribute to the development of SSc. A recent study reported that activated platelet-derived microparticles expressed DAMP HMGB1 and induced neutrophil activation in SSc patients, contributing to neutrophil extracellular trap production and autophagy [22]. Moreover, DAMP HMGB-1 induces proinflammatory effects partly through interaction with toll-like receptor 4 (TLR4), resulting in the activation of nuclear factor-kappa B (NF-kB) pathway and several inflammatory genes [42-45]. Notably, according to experimental findings of a myocardial infarction mouse model with cardiomyocyte-specific deletion of Capn4, Capn4 knock-out correlated with restoration of IкB protein and inhibition of NF- $\mathrm{kB}$ activation, resulting in the inhibition of proinflammatory cytokine expression and inflammatory cell infiltration in the Capn4 knock-out heart after myocardial infarction [46]. Consistent with previous results, our finding suggests that the toll-like receptor signaling pathway could be the potential mechanism that calpain and HMGB1 commonly function through bioinformatic analysis of integrative microarray datasets.

Most patients with SSc have circulating autoantibodies, such as anticentromere, anti-Scl-70, and antiRNA polymerase III. Clinicians commonly combine the measurement of circulating autoantibodies into the diagnostic evaluation of SSc. The presence of anti-Scl-70 antibodies in patients with SSc was discussed previously as a risk factor associated with progressive ILD [47]. However, none of these autoantibodies is absolute. Although the specificity of anti-Scl-70 antibodies is high, the sensitivity in detecting SSc is merely $34 \%$, and this increases slightly to $40 \%$ in detecting dSSc [48]. Inversely, in our study, we found that the elevation of serum calpain activity has a negative correlation with anti-Scl-70 antibodies, which suggested that due to the limitation of sensitivity and sample size, these autoantibodies should be interpreted by clinicians together with other clinical indicators in the evaluation of SSc or SSc-ILD. Also, the activity of serum calpain should be used as a guide for clinicians, but not as a definitive indicator for SSc or SScILD. Furthermore, future research based on a larger sample size is needed to confirm these findings.
A limitation of this study is that our limited samples from largely middle-aged female patients cannot represent the general population. Furthermore, another key limitation is the lack of ethnic or geographic diversity in our samples, which may potentially affect the reliability of the results. Therefore, our findings may not generalize total SSc or SSc-ILD patients. Further studies with larger sample sizes, more diverse ethnicities, and less heterogeneity are needed for the generalization of our findings. Despite the limitation, our study firstly identified the serum calpain activity was elevated in patients with SSc and highlighted the potential mechanisms for further research.

\section{Conclusions}

In conclusion, this is the first study that reports increased calpain activity in the serum of patients with SSc or SSc-ILD. We also highlight the correlations between serum calpain activity and HMGB1 levels. Serum calpain activity could potentially serve as a novel biomarker in patients with SSc-ILD and therapeutic targets for SSc or SSc-ILD. In the future, there remains a strong need for well-designed and prospective clinical studies with more homogenized populations and larger sample size to study the underlying function of calpain and HMGB1 in the development of SSc.

\section{Supplementary information}

Supplementary information accompanies this paper at https://doi.org/10. 1186/s13075-020-02195-y.

Additional file 1: Table S1. Details of SSC associated microarray datasets from GEO database.

Additional file 2: Figure S1. Genome-wide genes associated with calpain related genes expression. (a) Consensus matrix heat map for the chosen optimal cluster number $(k=2)$. (b) Consensus clustering cumulative distribution function (CDF) for $k=2$ to 9. (c) Relative change in area under CDF curve for $k=2$ to 9. (d) Volcano plot of differential genes between cluster 1 and cluster 2 . (e) Heat map of the two clusters. ${ }^{*} P<0.05$, ** $P<0.01$. (f) Protein-protein interactions network of differentially expressed genes between two clusters.

\section{Abbreviations}

SSc: Systemic sclerosis; ILD: Interstitial lung disease; PAH: Pulmonary arterial hypertension; EMT: Epithelial-to-mesenchymal transition; CAPNS1: Calpain small subunit 1; HMGB1: High mobility group box 1; DAMP: Damageassociated molecular pattern; HC: Healthy control subjects; CTD: Connective tissue diseases; PBMCs: Peripheral blood mononuclear cells; GEO: Gene Expression Omnibus; KEGG: Kyoto Encyclopedia of Genes and Genomes; GO: Gene Ontology; DEGs: Differently expressed genes; PPI: Protein-protein interaction; ULR: Univariate logistic regression; MLR: Multivariate logistic regression; ROC: Receiver operating characteristic curve; AUC: Area under the curve; dSSc: Diffuse cutaneous systemic sclerosis; ISSc: Limited cutaneous systemic sclerosis; mRSS: Modified Rodnan skin score; PCT: Plateletcrit; PLCR: Platelet large cell ratio; ESR: Erythrocyte sedimentation rate; MPV: Mean platelet volume

Acknowledgements

Special thanks to Dr. Zhen Yao for the continued support and company. 


\section{Authors' contributions}

Zheng JN, Li Y, and Wang Q designed the study. Shao WQ collected the blood samples. Zheng JN, Li Yang, and Yan YM did the statistical analyses and prepared figures. Zheng JN, Li Y, Yan YM, Yu Y, Shao WQ, and Wang Q reviewed the results and wrote the manuscript. All authors have made an intellectual contribution to the manuscript. The authors read and approved the final manuscript.

\section{Funding}

This study was supported by the grants awarded to Dr. Qiang Wang from the National Natural Science Foundation of China (81641087), the Key Biomedical Program of Science and Technology Commission of Shanghai Municipal (18401931700), the Research Fund of Shanghai Municipal Commission of Health and Family Planning (201640071, 2016ZJP001), and the Research and Development Fund of Zhongshan Hospital Affiliated to Fudan University (2016ZSFZ46).

\section{Availability of data and materials}

Publicly available datasets were analyzed in this study. Datasets (GSE40839, GSE48149, GSE76808, GSE81292, GSE33463, and GSE58095) were downloaded from GEO (http://www.ncbi.nlm.nih.gov/geo/).

\section{Ethics approval and consent to participate}

This study was carried out in accordance with the recommendations of Zhongshan Hospital Research Ethics Committee. The protocol was approved by the Ethical Committee of Zhongshan Hospital with the approval numberB2019-192R. The written informed consent was obtained from all patients.

\section{Consent for publication}

Informed consent was obtained from all participants for publication.

\section{Competing interests}

The authors declare that they have no competing interests.

\section{Author details}

'Department of Dermatology, Zhongshan Hospital, Fudan University, No. 180 Fenglin Road, Xuhui District, Shanghai 200032, People's Republic of China. ${ }^{2}$ Department of Stomatology, Zhongshan Hospital, Fudan University, Shanghai, People's Republic of China. ${ }^{3}$ State Key Laboratory of Molecular Engineering of Polymers, Fudan University, Shanghai, People's Republic of China. ${ }^{4}$ Department of Cardiology, Shanghai Institute of Cardiovascular Diseases, Zhongshan Hospital, Fudan University, Shanghai, People's Republic of China. ${ }^{5}$ Department of Cardiovascular Diseases, Key Laboratory of Viral Heart Diseases, Ministry of Public Health, Shanghai Institute of Cardiovascular Diseases, Zhongshan Hospital, Fudan University, Shanghai, People's Republic of China. ${ }^{6}$ Department of Laboratory Medicine, Zhongshan Hospital, Fudan University, Shanghai, People's Republic of China.

Received: 3 March 2020 Accepted: 23 April 2020

Published online: 11 May 2020

\section{References}

1. Denton CP, Khanna D. Systemic sclerosis. Lancet. 2017;390:1685-99.

2. Varga J, Abraham D. Systemic sclerosis: a prototypic multisystem fibrotic disorder. J Clin Invest. 2007;117:557-67.

3. Distler O, Cozzio A. Systemic sclerosis and localized scleroderma-current concepts and novel targets for therapy. Semin Immunopathol. 2016;38:87-95.

4. Friedman SL, Sheppard D, Duffield JS, Violette S. Therapy for fibrotic diseases: nearing the starting line. Sci Transl Med. 2013;5:167sr1.

5. Mostmans Y, Cutolo M, Giddelo C, Decuman S, Melsens K, Declercq H, Vandecasteele E, De Keyser F, Distler O, Gutermuth J, et al. The role of endothelial cells in the vasculopathy of systemic sclerosis: a systematic review. Autoimmun Rev. 2017;16:774-86.

6. Jimenez SA. Role of endothelial to mesenchymal transition in the pathogenesis of the vascular alterations in systemic sclerosis. ISRN Rheumatol. 2013;2013:835948.

7. Lafyatis R. Transforming growth factor $\beta$--at the centre of systemic sclerosis. Nat Rev Rheumatol. 2014;10:706-19.

8. Manetti M, Romano E, Rosa I, Guiducci S, Bellando-Randone S, De Paulis A, Ibba-Manneschi L, Matucci-Cerinic M. Endothelial-to-mesenchymal transition contributes to endothelial dysfunction and dermal fibrosis in systemic sclerosis. Ann Rheum Dis. 2017;76:924-34.

9. Franco SJ, Huttenlocher A. Regulating cell migration: calpains make the cut. J Cell Sci. 2005;118:3829-38.

10. Ono Y, Saido TC, Sorimachi H. Calpain research for drug discovery: challenges and potential. Nat Rev Drug Discov. 2016;15:854-76.

11. Goll DE, Thompson VF, Li H, Wei W, Cong J. The calpain system. Physiol Rev. 2003;83:731-801.

12. Ni R, Zheng D, Wang Q, Yu Y, Chen R, Sun T, Wang W, Fan GC, Greer PA, Gardiner RB, et al. Deletion of capn4 protects the heart against endotoxemic injury by preventing ATP synthase disruption and inhibiting mitochondrial superoxide generation. Circ Heart Fail. 2015;8:988-96.

13. Ni R, Zheng D, Xiong S, Hill DJ, Sun T, Gardiner RB, Fan GC, Lu Y, Abel ED, Greer PA, et al. Mitochondrial calpain-1 disrupts ATP synthase and induces superoxide generation in type 1 diabetic hearts: a novel mechanism contributing to diabetic cardiomyopathy. Diabetes. 2016;65:255-68.

14. Horowitz JC, Thannickal VJ. Epithelial-mesenchymal interactions in pulmonary fibrosis. Semin Respir Crit Care Med. 2006;27:600-12.

15. Tan WJ, Tan QY, Wang T, Lian M, Zhang L, Cheng ZS. Calpain 1 regulates TGF- $\beta 1$-induced epithelial-mesenchymal transition in human lung epithelial cells via PI3K/Akt signaling pathway. Am J Transl Res. 2017;9:1402-9.

16. Teng X, Ji C, Zhong H, Zheng D, Ni R, Hill DJ, Xiong S, Fan GC, Greer PA, Shen $Z$, et al. Selective deletion of endothelial cell calpain in mice reduces diabetic cardiomyopathy by improving angiogenesis. Diabetologia. 2019;62: $860-72$.

17. Wang Y, Zheng D, Wei M, Ma J, Yu Y, Chen R, Lacefield JC, Xu H, Peng T. Over-expression of calpastatin aggravates cardiotoxicity induced by doxorubicin. Cardiovasc Res. 2013;98:381-90.

18. Scaffidi P, Misteli T, Bianchi ME. Release of chromatin protein HMGB1 by necrotic cells triggers inflammation. Nature. 2002;418:191-5.

19. Mandke $P$, Vasquez KM. Interactions of high mobility group box protein 1 (HMGB1) with nucleic acids: implications in DNA repair and immune responses. DNA Repair (Amst). 2019:83:102701.

20. Yoshizaki A, Komura K, Iwata Y, Ogawa F, Hara T, Muroi E, Takenaka M, Shimizu K, Hasegawa M, Fujimoto M, et al. Clinical significance of serum HMGB-1 and sRAGE levels in systemic sclerosis: association with disease severity. J Clin Immunol. 2009;29:180-9.

21. Bernard NJ. HMGB1(+) platelet microparticles damage the endothelium. Nat Rev Rheumatol. 2018;14:499.

22. Maugeri N, Capobianco A, Rovere-Querini P, Ramirez GA, Tombetti E, Valle PD, Monno A, D'Alberti V, Gasparri AM, Franchini S, et al. Platelet microparticles sustain autophagy-associated activation of neutrophils in systemic sclerosis. Sci Transl Med. 2018;10:eaao3089.

23. Maugeri N, Franchini S, Campana L, Baldini M, Ramirez GA, Sabbadini MG, Rovere-Querini P, Manfredi AA. Circulating platelets as a source of the damage-associated molecular pattern HMGB1 in patients with systemic sclerosis. Autoimmunity. 2012;45:584-7.

24. Kelton JG, Warkentin TE, Hayward CP, Murphy WG, Moore JC. Calpain activity in patients with thrombotic thrombocytopenic purpura is associated with platelet microparticles. Blood. 1992;80:2246-51.

25. van den Hoogen F, Khanna D, Fransen J, Johnson SR, Baron M, Tyndall A, Matucci-Cerinic M, Naden RP, Medsger TA Jr, Carreira PE, et al. 2013 classification criteria for systemic sclerosis: an American college of rheumatology/European league against rheumatism collaborative initiative. Ann Rheum Dis. 2013;72:1747-55.

26. McLaughlin W, Archer SL, Badesch DB, Barst RJ, Farber HW, Lindner JR, Mathier MA, MD MG, Park MH, Rosenson RS, et al. ACCF/AHA 2009 expert consensus document on pulmonary hypertension a report of the American College of Cardiology Foundation Task Force on Expert Consensus Documents and the American Heart Association developed in collaboration with the American College of Chest Physicians; American Thoracic Society, Inc.; and the Pulmonary Hypertension Association. J Am Coll Cardiol. 2009; 53:1573-619.

27. Wilkerson MD, Hayes DN. ConsensusClusterPlus: a class discovery tool with confidence assessments and item tracking. Bioinformatics. 2010;26:1572-3.

28. Letavernier E, Zafrani L, Perez J, Letavernier B, Haymann JP, Baud L. The role of calpains in myocardial remodelling and heart failure. Cardiovasc Res. 2012:96:38-45.

29. Miyazaki T, Miyazaki A. Dysregulation of calpain proteolytic systems underlies degenerative vascular disorders. J Atheroscler Thromb. 2018; 25:1-15. 
30. Li FZ, Cai PC, Song LJ, Zhou LL, Zhang Q, Rao SS, Xia Y, Xiang F, Xin JB, Greer PA, et al. Crosstalk between calpain activation and TGF-beta1 augments collagen-I synthesis in pulmonary fibrosis. Biochim Biophys Acta. 1852:2015:1796-804.

31. Liu Y, Liu B, Zhang GQ, Zou JF, Zou ML, Cheng ZS. Calpain inhibition attenuates bleomycin-induced pulmonary fibrosis via switching the development of epithelial-mesenchymal transition. Naunyn Schmiedeberg's Arch Pharmacol. 2018;391:695-704.

32. Tabata C, Tabata R, Nakano T. The calpain inhibitor calpeptin prevents bleomycin-induced pulmonary fibrosis in mice. Clin Exp Immunol. 2010;162: 560-7.

33. Tan WJ, Tan QY, Wang T, Lian M, Zhang L, Cheng ZS. Calpain 1 regulates TGF-beta1-induced epithelial-mesenchymal transition in human lung epithelial cells via PI3K/Akt signaling pathway. Am J Transl Res. 2017;9:14029 .

34. Song $L$, Xiang F, Ye H, Huang H, Yang J, Yu F, Xiong L, Xu JJ, Greer PA, Shi $\mathrm{HZ}$, et al. Inhibition of angiotensin II and calpain attenuates pleural fibrosis. Pulm Pharmacol Ther. 2018;48:46-52.

35. Scherlinger M, Guillotin V, Truchetet ME, Contin-Bordes C, Sisirak V, Duffau P, Lazaro E, Richez C, Blanco P. Systemic lupus erythematosus and systemic sclerosis: all roads lead to platelets. Autoimmun Rev. 2018;17:625-35.

36. Guiducci S, Distler JH, Jungel A, Huscher D, Huber LC, Michel BA, Gay RE, Pisetsky DS, Gay S, Matucci-Cerinic M, et al. The relationship between plasma microparticles and disease manifestations in patients with systemic sclerosis. Arthritis Rheum. 2008:58:2845-53.

37. Shu X, Peng Q, Lu X, Wang G. HMGB1 may be a biomarker for predicting the outcome in patients with polymyositis /dermatomyositis with interstitial lung disease. PLoS One. 2016;11:e0161436.

38. Ji J, Fu T, Dong C, Zhu W, Yang J, Kong X, Zhang Z, Bao Y, Zhao R, Ge X, et al. Targeting HMGB1 by ethyl pyruvate ameliorates systemic lupus erythematosus and reverses the senescent phenotype of bone marrowmesenchymal stem cells. Aging (Albany NY). 2019;11:4338-53.

39. Pisetsky DS. The complex role of DNA, histones and HMGB1 in the pathogenesis of SLE. Autoimmunity. 2014;47:487-93.

40. Syahidatulamali CS, Wan Syamimee WG, Azwany YN, Wong KK, Che Maraina CH. Association of anti-CLIC2 and anti-HMGB1 autoantibodies with higher disease activity in systemic lupus erythematosus patients. J Postgrad Med. 2017;63:257-61.

41. Biscetti F, Flex A, Alivernini S, Tolusso B, Gremese E, Ferraccioli G. The role of high-mobility group box-1 and its crosstalk with microbiome in rheumatoid arthritis. Mediat Inflamm. 2017;2017:5230374.

42. Yang $\mathrm{H}$, Wang H, Ju Z, Ragab AA, Lundback P, Long W, Valdes-Ferrer SI, He M, Pribis JP, Li J, et al. MD-2 is required for disulfide HMGB1-dependent TLR4 signaling. J Exp Med. 2015;212:5-14.

43. Anton M, Alen F, Gomez de Heras R, Serrano A, Pavon FJ, Leza JC, GarciaBueno B, Rodriguez de Fonseca F, Orio L. Oleoylethanolamide prevents neuroimmune HMGB1/TLR4/NF-kB danger signaling in rat frontal cortex and depressive-like behavior induced by ethanol binge administration. Addict Biol. 2017;22:724-41.

44. Koh WU, Kim J, Lee J, Song GW, Hwang GS, Tak E, Song JG. Remote ischemic preconditioning and diazoxide protect from hepatic ischemic reperfusion injury by inhibiting HMGB1-induced TLR4/MyD88/NF-kappaB signaling. Int J Mol Sci. 2019;20:5899.

45. Liu AH, Wu YT, Wang YP. MicroRNA-129-5p inhibits the development of autoimmune encephalomyelitis-related epilepsy by targeting HMGB1 through the TLR4/NF-kB signaling pathway. Brain Res Bull. 2017;132:139-49.

46. Ma J, Wei M, Wang Q, Li J, Wang H, Liu W, Lacefield JC, Greer PA, Karmazyn M, Fan GC, et al. Deficiency of Capn4 gene inhibits nuclear factor-kappaB (NF-kappaB) protein signaling/inflammation and reduces remodeling after myocardial infarction. J Biol Chem. 2012;287:27480-9.

47. Khanna D, Tashkin DP, Denton CP, Renzoni EA, Desai SR, Varga J. Etiology, risk factors, and biomarkers in systemic sclerosis with interstitial lung disease. Am J Respir Crit Care Med. 2020;201:650-60.

48. Spencer-Green G, Alter D, Welch HG. Test performance in systemic sclerosis: anti-centromere and anti-Scl-70 antibodies. Am J Med. 1997;103:242-8.

\section{Publisher's Note}

Springer Nature remains neutral with regard to jurisdictional claims in published maps and institutional affiliations.

\section{Ready to submit your research? Choose BMC and benefit from}

- fast, convenient online submission

- thorough peer review by experienced researchers in your field

- rapid publication on acceptance

- support for research data, including large and complex data types

- gold Open Access which fosters wider collaboration and increased citations

- maximum visibility for your research: over $100 \mathrm{M}$ website views per year

At BMC, research is always in progress.

Learn more biomedcentral.com/submissions 